\title{
Hospitalizations for viral respiratory infections in children under 2 years of age: epidemiology and in-hospital complications
}

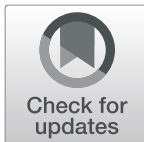

Jessie N. Zurita-Cruz ${ }^{1,2,3}$, Alejandro Gutierrez-Gonzalez ${ }^{4}$, Leticia Manuel-Apolinar ${ }^{5}$, José Esteban Fernández-Gárate ${ }^{6}$, María Luisa Arellano-Flores ${ }^{5}$, Roberto Alejandro Correa Gonzalez ${ }^{7}$ Guillermo Vázquez-Rosales ${ }^{8}$, Rocio Sanchez-Armas ${ }^{3}$ and Nelly Cisneros-González ${ }^{6^{*}}$

\begin{abstract}
Background: Viral respiratory infections (VRIs) are a frequent cause of hospitalization in children under 24 months of age. A history of prematurity or heart disease may be a risk factor for complications in patients hospitalized for VRI. The objective was to describe epidemiological data for children hospitalized for IRV and aged 1 to 24 months and to identify risk factors for the presence of in-hospital complications and mortality over a period of 5 years.
\end{abstract}

Methods: This was a cross-sectional study. Patients registered with VRI codes B974, J12, J120-J129X, J168, J17, J171, J178, J20, J203-J209, J21, J210, J211, J218, J219 (based on International Classification of Diseases [ICD-10]) from 2013 to 2017 were included. Three subanalyses were performed to compare [1] patients with pathological history (prematurity, bronchopulmonary dysplasia [BPD] and congenital heart disease [CHD]), [2] diagnoses (pneumonia, acute bronchitis, and acute bronchiolitis), and [3] admission to the pediatric intensive care unit. Days of hospital stay, in-hospital complications, invasive medical procedure and mortality were analyzed. Statistical analysis: VRI hospitalization prevalence was described. For comparison between groups, Student's t-test, ANOVA and the Chi2 test were applied. To identify factors related to days of hospital stay, in-hospital complications and mortality, a linear and logistic regression model was performed.

Results: A total of 66,304 hospitalizations were reported. The average age was 14.7 weeks; hospitalization events were higher in winter (39\%), followed by autumn (27.3\%). A total of 371 (0.56\%) patients died. A total of 7068 (10.6\%) hospitalized patients with pathological histories were identified. The presence of BPD (coefficient $=1.6)$, CHD (coefficient $=1.2)$, diagnosis of pneumonia (coefficient $=1.2$ ), in-hospital complications (coefficient $=2.1$ ) and invasive medical procedures (coefficient = 15.7) were the most common factors that increased the length of hospital stay. Risk factors for in-hospital complications and mortality were invasive medical procedure $(\mathrm{OR}=3.3$ \& 11.7), $\mathrm{BPD}(\mathrm{OR}=1.8$ \& 1.6), $\mathrm{CHD}(\mathrm{OR}=4.6$ \& 3.4) and diagnosis of pneumonia $(\mathrm{OR}=1.8 \& 4.2)$.

Conclusions: Risk factors for morbidity and mortality in patients hospitalized for VRIs are BPD and CHD, diagnosis of pneumonia and invasive medical procedure.

Keywords: Respiratory tract infection, Viruses, Epidemiology, Bronchiolitis, Mexico

\footnotetext{
* Correspondence: zuritain@gmail.com

${ }^{6}$ Epidemiological Surveillance Coordination, Instituto Mexicano del Seguro Social (IMSS), Mexico City, Mexico

Full list of author information is available at the end of the article
}

(C) The Author(s). 2020 Open Access This article is licensed under a Creative Commons Attribution 4.0 International License, which permits use, sharing, adaptation, distribution and reproduction in any medium or format, as long as you give appropriate credit to the original author(s) and the source, provide a link to the Creative Commons licence, and indicate if changes were made. The images or other third party material in this article are included in the article's Creative Commons licence, unless indicated otherwise in a credit line to the material. If material is not included in the article's Creative Commons licence and your intended use is not permitted by statutory regulation or exceeds the permitted use, you will need to obtain permission directly from the copyright holder. To view a copy of this licence, visit http://creativecommons.org/licenses/by/4.0/ The Creative Commons Public Domain Dedication waiver (http://creativecommons.org/publicdomain/zero/1.0/) applies to the data made available in this article, unless otherwise stated in a credit line to the data. 


\section{Background}

Viral respiratory infections (VRIs), including bronchiolitis, are the main cause of hospitalization in pediatric patients under 2 years of age [1]. It is estimated that hospital expenses secondary to this disease reach up to $\$ 1.4$ billion, constituting a significant public health burden [2]. Research on hospitalizations for VRI have shown that the main etiologic agent is respiratory syncytial virus (RSV) [3].

A complete clinical examination is indispensable in the initial evaluation of patients. Evidence of inadequate feeding or fluid intake, history of apnea, lethargy, moderate to severe respiratory distress (nasal flutter, tachypnea, respiratory whining, retractions or cyanosis) and low oxygen saturation at ambient air require hospitalization $[3,4]$. Therefore, admission to the pediatric intensive care unit (PICU) in patients with clinical signs of exhaustion, markers of acute respiratory failure or apnea should be considered [5]. In general, an etiological diagnosis is made with clinical data, and an age less than 2 years invokes high suspicion of RSV [6].

Patients with a history of prematurity have a higher risk of complications in VRIs due to a lack of lung development and an inadequate immune system response. The condition of bronchopulmonary dysplasia (BPD), in which structural abnormalities persist in the lungs, is also a complication that results in greater complexity and vulnerability of torpid evolution presentation in VRI [7-10]. Another group of patients with a high risk of mortality secondary to VRI are those diagnosed with congenital heart disease (CHD), which may be related to multiple physiological factors, including baseline compromised cardiorespiratory function, changed mechanisms of pulmonary regulation, ventilation - perfusion mismatch, pulmonary hypertension and/or an inadequate immune response secondary to malnutrition that some patients with CHD may present $[11,12]$.

To date, there are no updated epidemiological data for this disease in Mexico or information about the risk factors related to hospital complications in our population. The objective of our study was to describe the epidemiological data for children hospitalized for VRI and aged from 1 to 24 months and to identify risk factors for the presence of in-hospital complications and mortality in beneficiaries of the Mexican Social Security Institute (IMSS) over a period of 5 years (January 2013 to December 2017).

\section{Methods}

This was a cross-sectional study. The patients were clinically diagnosed by doctors at IMSS. The data used in this study were obtained from the System of Information of Integral Health Care and the hospital records of the System of Medical Statistics (DataMart) of the IMSS and the databases of Family Medicine Units. At the IMSS, medical attention is classified into three levels: 1st-level facilities perform preventive measures and treat acute and chronic pathologies without complications; 2nd-level facilities address complicated pathologies, chirurgic interventions, and treatments that require hospitalization; and 3rd-level facilities are equipped to treat individuals with complex and complicated diseases. At IMSS database, each patient is identified uniquely, and his/her record is updated accordingly across all clinics the patient may have been treated. Diseases are registered through the codes of the International Classification of Diseases (ICD 10).

The data in the database were compiled by doctors who attend and diagnose patients visiting hospitals affiliated with the IMSS; the data are validated by a team of engineers in computer systems and are analyzed by statisticians affiliated with specialized centers strategically located at regional and state levels.

For this study, patients aged 1 to 24 months hospitalized for severe acute respiratory infection with respiratory distress, febrile syndrome, inadequate oral intake or dehydration from January 2013 to December 2017 in IMSS hospitals were included. Patients included were described using the following ICD-10 codes: B974, which includes RSV; J12, which includes viral (J120-J129X) or nonspecific (J168, J17, J171, J178) pneumonia, acute bronchitis (J20, J203-J209), and acute bronchiolitis (J21, J210, J211, J218, J219).

The study included patients who, according to records, were first hospitalized at the IMSS for respiratory tract infections.

Patients with immunodeficiency (D81-D84), neurological disorders (G40-G41, G71, G80-G83), airway malformations (Q30-Q34) or incomplete data were excluded.

In-hospital complications were defined as any event or condition detrimental to the patient's health, as caused by an unintentional injury and recorded by the medical and nursing staff during hospitalization. In-hospital complications were grouped and labeled as infectious, respiratory, metabolic and cardiovascular complications.

In addition, codes for respiratory complications such as nonviral pneumonia (J13, J13X, J14, J15, J151, J152, J156, J158, J159, J16, J181, J182), respiratory failure (J96, J960, J969), and nonspecific respiratory disorder (J988, J989) were included in the diagnoses.

An invasive medical procedure was defined as deliberate access to the body through an incision or a percutaneous puncture, where instrumentation is used in addition to the puncture needle or instrumentation through a natural orifice, and performed by trained professionals who use instruments; only invasive procedures related to VRI were included. 
Patients were classified according to pathological history, including history of BPD, prematurity and CHD.

A history of prematurity was identified by relevant ICD-10 codes (P070, P072, P073). The patients were subclassified into premature and extremely premature groups according to the history of weeks of gestational age (wGA). Prematurity was defined as 29-36 wGA at birth and extremely premature as $<29$ wGA at birth. The presence of BPD was identified by code P271, and congenital heart disease with hemodynamic compromise was identified by codes Q20-Q26.

The criteria for severe acute respiratory infection were considered when the patient required endotracheal intubation and was admitted to the PICU. A subanalysis of the patients admitted to the PICU was performed.

Of the included patients, data regarding sex, age, location, month of hospitalization, days of hospital stay and complications during stay were collected, as was the reason for hospital discharge.

The primary outcomes that were included were the length of hospital stay, in-hospital complications, invasive medical procedure and mortality.

\section{Statistical analysis}

Quantitative variables are presented as the mean, standard deviation, minimum and maximum. Qualitative variables are presented as proportions and frequencies. Three subanalyses were performed to compare (1) patients with pathological history (prematurity, BPD and CHD), (2) admission diagnoses (pneumonia, acute bronchitis, and acute bronchiolitis), and (3) admission to the PICU.

A nonnormal distribution was observed for quantitative variables (age and length of hospital stay) using the Kolmogorov-Smirnov test; therefore, log-transformation was used for the statistical analysis. Student's t-test, ANOVA, and $x^{2}$ analyses were applied for inferences.

To identify factors related to the length of hospital stay, multiple linear regression was performed; the linear regression model met the assumptions of linearity, normality, homoscedasticity and independence. To identify factors related to in-hospital complications and mortality, a multiple logistic regression model was constructed with "step backward" modeling, and a fitting model was obtained, whereby the noncollinearity of the variables was confirmed.

A value of $p<0.05$ was considered statistically significant.

STATA v.12.0 was used for the statistical analyses.

The protocol was approved by the National Research Ethics Committee, which belongs to the Mexican Institute of Social Security. This committee is the body in charge of evaluating research projects at the national level.

\section{Results}

From 2013 to 2017, 66,304 patients from 1 month to 24 months of age were hospitalized due to VRI. For the general characteristics of the population, a male predominance was observed (61.1\%), with an average age of 14.7 weeks (Table 1 ).

The average number of hospitalized patients per year was 13,260 , with a gradual decrease in hospitalizations over the course of 5 years. Hospitalizations according to the season of the year were greater in winter $(39.08 \%)$, followed by autumn (27.29\%). The average hospital stay was 4.1 days, with a maximum stay of 205 days (Table 1 ). The most frequent hospitalization diagnosis was acute bronchiolitis $(56.93 \% n=37,747)$, followed by pneumonia $(38.32 \%, n=25,411)$ and acute bronchitis $(4.74 \% n=$ 3146). A total of 7068 (10.66\%) hospitalized patients with a pathological history were identified; 329 patients $(0.50 \%)$ required a stay in the PICU due to the severity of the disease. Of the total hospitalized patients with a history of prematurity, 123 had a history of extreme prematurity, of which six (4.8\%) required invasive medical procedures, two (1.6\%) had in-hospital complications, and three $(2.4 \%)$ required hospital stay in the PICU; three $(2.4 \%)$ died.

During the hospital stay, a low frequency of complications was reported $(1.22 \% n=812)$, with respiratory complications being the most frequent $(41.40 \% n=336)$. Invasive medical procedures were performed for $552 \mathrm{pa}$ tients $(0.83 \%)$, and of these interventions, the most common was the placement of a venous catheter $(n=302)$, followed by endotracheal intubation $(n=170)$ and bronchoscopy with or without biopsy $(n=80)$ (Table 2).

Table 1 General characteristics of 66,304 patients aged 1 to 24 months hospitalized for viral respiratory infections from 2013 to 2017 in the IMSS

\begin{tabular}{lll}
\hline & & Frequency (\%) \\
\hline Age (weeks) & & $14.7 \pm 15.3(5-$ \\
& & $102)$ \\
Sex Male & & $40,450(61.01)$ \\
Hospitalization according to the season of & Spring & $14,561(21.96)$ \\
the year & Summer & $7737(11.67)$ \\
& Fall & $18,093(27.29)$ \\
& Winter & $25,913(39.08)$ \\
Hospitalization year & 2013 & $17,378(26.21)$ \\
& 2014 & $13,185(19.89)$ \\
& 2015 & $13,773(20.77)$ \\
& 2016 & $10,810(16.30)$ \\
Days of hospital stay ${ }^{a}$ & 2017 & $11,158(16.83)$ \\
Presence of pathological history & & $4.1 \pm 4.4(1-205)$ \\
\hline
\end{tabular}

${ }^{\mathrm{a}}$ Mean \pm standard deviation (minimum-maximum) 
Table 2 Hospital evolution of 66,304 patients aged 1 to 24 months due to viral respiratory infections from 2013 to 2017 in the IMSS

\begin{tabular}{|c|c|c|}
\hline & & $\begin{array}{l}\text { Frequency } \\
\text { (\%) }\end{array}$ \\
\hline \multicolumn{2}{|c|}{ In-hospital complications } & $812(1.22)$ \\
\hline \multirow{4}{*}{$\begin{array}{l}\text { Type of in-hospital } \\
\text { complications }\end{array}$} & Respiratory & $336(41.40)$ \\
\hline & Cardiovascular & $240(29.56)$ \\
\hline & Metabolic & $151(18.60)$ \\
\hline & Infectious & $85(10.44)$ \\
\hline \multirow[t]{5}{*}{ Pathological history } & Prematurity & $\begin{array}{l}3234 \\
(45.76)\end{array}$ \\
\hline & $\begin{array}{l}\text { Bronchopulmonary dysplasia } \\
\text { (BPD) }\end{array}$ & $\begin{array}{l}2467 \\
(34.90)\end{array}$ \\
\hline & Congenital heart disease & $762(10.78)$ \\
\hline & $\begin{array}{l}\text { Congenital heart disease \& } \\
\text { prematurity }\end{array}$ & $327(4.63)$ \\
\hline & $\begin{array}{l}\text { Congenital heart disease \& } \\
\text { BPD }\end{array}$ & $278(3.93)$ \\
\hline \multicolumn{2}{|c|}{ Invasive medical procedure } & $552(0.83)$ \\
\hline \multicolumn{2}{|c|}{ Admitted to Pediatric Intensive Care Unit } & $329(0.50)$ \\
\hline \multicolumn{2}{|l|}{ Mortality } & $371(0.56)$ \\
\hline
\end{tabular}

Mortality among the hospitalized patients was $0.56 \%$ $(n=371)$, with an average age of 13 weeks. The most frequent diagnosis was respiratory failure secondary to pneumonia $(n=182)$, followed by heart failure $(n=98)$, septic shock $(n=55)$, hydroelectrolytic imbalance $(n=$ $20)$, and others $(n=6)$ (Table 2$)$. Of the deceased patients, $38.8 \%(n=144)$ had a pathological history $(n=89$ with prematurity, $n=21$ with BPD, $n=34$ with $\mathrm{CHD}$ ). Of the patients who died from respiratory failure, 19 had BPD. Among the patients with heart failure, 34 had CHD. In addition, of the 45 patients with septic shock, 35 had a history of prematurity, 3 had a history of extreme prematurity, and two had BPD.

Within this group of hospitalized patients, multiple factors were identified that might impact in-hospital complications and mortality. Therefore, a subanalysis according to the type of diagnosis at admission, presence of pathological history and stay in the PICU was performed. Regarding the admission diagnosis, the patients with a diagnosis of pneumonia had a longer hospital stay (pneumonia 5.09 vs. bronchitis 3 vs. bronchiolitis 3.5 days), a higher proportion of in-hospital complications (pneumonia $1.83 \%$ vs. bronchitis $0.45 \%$ vs. bronchiolitis $0.88 \%$ ) and invasive medical procedures (pneumonia $1.64 \%$ vs. bronchitis $0.64 \%$ vs. bronchiolitis $0.31 \%$ ), a longer stay in the PICU (pneumonia $1.07 \%$ vs. bronchitis $0.45 \%$ vs. bronchiolitis $0.11 \%$ ) and higher mortality (pneumonia $1.14 \%$ vs. bronchitis $0.06 \%$ vs. bronchiolitis $0.21 \%$ ) than patients who had bronchitis and bronchiolitis (Table 3). When dividing the patients according to the presence of a pathological history, the length of hospital stay (6.09 vs. 3.94 days), the presence of complications (5.8\% vs. $1.31 \%)$, invasive medical procedure $(0.67 \%$ vs. $2.52 \%)$ and death $(0.4 \%$ vs. $2.16 \%)$ were greater in patients with pathological history than in those without them (Table 3). The patients who were admitted to the PICU had a longer hospital stay (21.6 vs. 4 days) and a higher proportion of in-hospital complications $(6.69 \%$ vs. 1.20$)$ and invasive medical procedures (100\% vs. $0.34 \%)$ and mortality $(9.12 \%$ vs. $0.52 \%)$ than patients who were not admitted to the PICU. None of these comparisons identified that age had an impact on the progression of the cases (Table 3 ).

To identify factors related to the length of hospital stay, several multivariate models were built. We observed that the presence of BPD (coefficient $=1.64$, CI95\% 1.37 to 1.90 ), CHD (coefficient $=1.24$, CI95\% 1.59 to 1.87 ), diagnosis of pneumonia (coefficient $=1.21$, CI95\% 1.14 to 1.27), in-hospital complications (coefficient $=2.19$, CI95\% 1.90 to 2.48 ) and invasive medical procedures (coefficient $=15.78, C I 95 \% 15.24$ to 16.32 ) were the most common factors that increased the length of hospital stay (Table 4).

To identify factors that impact hospital complications, a multivariate model was evaluated, and it was observed that the most influential factors were invasive medical procedures $(\mathrm{OR}=3.35 \mathrm{CI95 \%} 2.35$ to 4.77 ) and $\mathrm{CHD}$ (OR 4.69 CI95\% 3.97 to 5.55), followed by BPD, a history of prematurity and diagnosis of pneumonia (Table 5.A).

The multivariate model for factors that impact mortality showed that the most influential factors were invasive medical procedures $(\mathrm{OR}=11.17$, CI95\% 8.14 to 15.33$)$, diagnosis of pneumonia (OR 4.25, CI95\% 3.30 to 5.47 ) and CHD (OR 3.40, CI95\% 2.65 to 4.37), female sex and BPD (Table 5.B).

\section{Discussion}

The analysis in our study allowed us to recognize that a history of CHD, BPD, diagnosis at pneumonia and invasive medical procedures were risk factors for the presence of in-hospital complications and mortality in children under 24 months of age hospitalized for VRI.

$\mathrm{BPD}$ is the most frequent chronic lung disease in infancy [13]; compared to healthy preterm infants, these patients have been shown to have fewer mature macrophages in the airways in the immediate perinatal period. The circulating monocytes of these patients also show decreased HLA-DR expression [14]. These conditions, both prematurity and BPD, render these patients more vulnerable to serious complications during VRI [7-10]. In our study group, BPD proved to be a risk factor for mortality $(\mathrm{OR}=1.69)$, mainly because BDP has a mortality rate of 40 to $5 \%$, depending on the wGA [15]. In 
Table 3 Comparison of the characteristics of patients with and without Pathological history, diagnosis at admission and admitted to Pediatric Intensive Care Unit from 1 to 24 months of age hospitalized for viral respiratory infections from 2013 to 2017 in the IMSS

\begin{tabular}{|c|c|c|c|c|c|c|c|c|c|c|}
\hline & \multicolumn{3}{|c|}{ Pathological history } & \multicolumn{4}{|c|}{ Diagnosis at admission } & \multicolumn{3}{|c|}{$\begin{array}{l}\text { Admitted to Pediatric Intensive } \\
\text { Care Unit }\end{array}$} \\
\hline & $\begin{array}{l}\text { Without } \\
n=59,236\end{array}$ & $\begin{array}{l}\text { With } \\
n=7068\end{array}$ & $p$ & $\begin{array}{l}\text { Pneumonia } \\
n=25,411\end{array}$ & $\begin{array}{l}\text { Bronchitis } \\
n=3146\end{array}$ & $\begin{array}{l}\text { Bronchiolitis } \\
n=37,747\end{array}$ & $p$ & $\begin{array}{l}\text { No } n=65, \\
975\end{array}$ & Yes $n=329$ & $p$ \\
\hline \multicolumn{11}{|l|}{ Frequency (\%) } \\
\hline Age (weeks)* & $\begin{array}{l}14.7 \pm 15.3 \\
(5-102)\end{array}$ & $\begin{array}{l}14.6 \pm 14.8 \\
(5-102)\end{array}$ & 0.758 & $\begin{array}{l}14.8 \pm 16.0 \\
(5-102)\end{array}$ & $\begin{array}{l}14.3 \pm 15.5 \\
(5-102)\end{array}$ & $\begin{array}{l}14.7 \pm 14.7 \\
(5-102)\end{array}$ & 0.786 & $\begin{array}{l}14.7 \pm 15.3 \\
(5-102)\end{array}$ & $\begin{array}{l}14.5 \pm 14.5 \\
(5-102)\end{array}$ & 0.832 \\
\hline Sex Male & $\begin{array}{l}36,283 \\
(61.25)\end{array}$ & $\begin{array}{l}4166 \\
(58.94)\end{array}$ & $<0.001$ & $\begin{array}{l}15,092 \\
(59.39)\end{array}$ & $1875(59.60)$ & $\begin{array}{l}23,482 \\
(62.21)\end{array}$ & $<0.001$ & $\begin{array}{l}36,283 \\
(61.25)\end{array}$ & $\begin{array}{l}4166 \\
(58.94)\end{array}$ & $<0.001$ \\
\hline $\begin{array}{l}\text { Hospital stay } \\
(\text { days)* }\end{array}$ & $\begin{array}{l}3.9 \pm 3.8 \\
(1-139)\end{array}$ & $\begin{array}{l}6.0 \pm 7.6 \\
(1-205)\end{array}$ & $<0.001$ & $\begin{array}{l}5.09 \pm 5.7 \\
(1-205)\end{array}$ & $\begin{array}{l}3.0 \pm 3.4 \\
(1-103)\end{array}$ & $\begin{array}{l}3.5 \pm 3.2 \\
(1-119)\end{array}$ & $<0.001$ & $\begin{array}{l}4.0 \pm 4.0 \\
1-205)\end{array}$ & $\begin{array}{l}21.6 \pm 22.1 \\
(1-139)\end{array}$ & $<0.001$ \\
\hline $\begin{array}{l}\text { In-hospital } \\
\text { complications }\end{array}$ & $540(0.91)$ & $272(3.85)$ & $<0.001$ & $\begin{array}{l}466 \\
(1.83)\end{array}$ & $14(0.45)$ & $\begin{array}{l}332 \\
(0.88)\end{array}$ & $<0.001$ & $\begin{array}{l}790 \\
(1.20)\end{array}$ & $22(6.69)$ & $<0.001$ \\
\hline $\begin{array}{l}\text { Invasive medical } \\
\text { procedure }\end{array}$ & $373(0.63)$ & $179(2.53)$ & $<0.001$ & $\begin{array}{l}416 \\
(1.64)\end{array}$ & $20(0.64)$ & $\begin{array}{l}116 \\
(0.31)\end{array}$ & $<0.001$ & $\begin{array}{l}223 \\
(0.34)\end{array}$ & $329(100)$ & $<0.001$ \\
\hline $\begin{array}{l}\text { Pediatric Intensive } \\
\text { Care Unit }\end{array}$ & $221(0.37)$ & $108(1.53)$ & $<0.001$ & $\begin{array}{l}272 \\
(1.07)\end{array}$ & $14(0.45)$ & $\begin{array}{l}43 \\
(0.11)\end{array}$ & $<0.001$ & - & - & - \\
\hline Mortality & $227(0.38)$ & $144(2.04)$ & $<0.001$ & $\begin{array}{l}290 \\
(1.14)\end{array}$ & $2(0.06)$ & $\begin{array}{l}79 \\
(0.21)\end{array}$ & $<0.001$ & $\begin{array}{l}341 \\
(0.52)\end{array}$ & $30(9.12)$ & $<0.00$ \\
\hline
\end{tabular}

Mean \pm standard deviation (minimum-maximum)

patients with CHD and BPD who have an increased risk of presenting pulmonary hypertension due to their pathology, the presence of a VRI can worsen this secondary pulmonary hypertension due to multiple factors, including lung volume changes either with atelectasis or hyperinflation, hypoxic vasoconstriction, endothelin pathway, and Th2-skewed immune response [16-18]. This adverse environment that occurs in patients with $\mathrm{CHD}$ constitutes a risk for developing heart failure, which causes a longer hospital length of stay and increased mortality [16]. As we observed in this study, in which patients died of heart failure, $34.6 \%$ had a pathological history of CHD.

There are multiple factors associated with in-hospital complications in this group of patients, and prematurity

Table 4 Multiple linear regression analysis to identify the factors related to the days of hospital stay of children 1 to 24 months of age hospitalized for viral respiratory infections ( $n=66,304)$

\begin{tabular}{llll}
\hline & Coefficient & $\begin{array}{l}\text { Confidence } \\
\text { interval } 95 \%\end{array}$ & $p$ \\
\hline Sex female & 0.06 & 0.002 to 0.13 & 0.043 \\
History of prematurity & 0.55 & 0.408 to 0.707 & $<0.001$ \\
Bronchopulmonary dysplasia & 1.64 & 1.37 to 1.90 & $<0.001$ \\
Congenital heart disease & 1.73 & 1.59 to 1.87 & $<0.001$ \\
In-hospital complications & 2.19 & 1.90 to 2.48 & $<0.001$ \\
Invasive medical procedures & 15.78 & 15.24 to 16.32 & $<0.001$ \\
Admitted to Pediatric Intensive & 0.78 & 0.08 to 1.48 & 0.029 \\
Care Unit & & & \\
Diagnosis at pneumonia & 1.21 & 1.14 to 1.27 & $<0.001$ \\
\hline
\end{tabular}

has been demonstrated; the OR described in a metaanalysis was 1.96 (95\% CI 1.44-2.67), which was greater than that in our study $(\mathrm{OR}=1.47)$. Premature birth interrupts the transfer of maternal antibodies, and maturation of the immune system occurs at 6 months of life;

Table 5 Logistic regression analysis to identify the factors that impact on in-hospital complications (A) and mortality (B) of children hospitalized for viral respiratory infections from 2013 to 2017 in the IMSS $(n=66,304)$

A. Intrahospital complications

\begin{tabular}{|c|c|c|c|}
\hline & OR & $\begin{array}{l}\text { Confidence } \\
\text { interval 95\% }\end{array}$ & $\mathrm{p}$ \\
\hline History of prematurity & 1.47 & 1.14 to 1.89 & 0.002 \\
\hline Bronchopulmonary dysplasia & 1.83 & 1.32 to 2.53 & $<0.001$ \\
\hline Congenital heart disease & 4.69 & 3.97 to 5.55 & $<0.001$ \\
\hline Invasive medical procedures & 3.35 & 2.35 to 4.77 & $<0.001$ \\
\hline Diagnosis at pneumonia & 1.84 & 1.59 to 2.12 & $<0.001$ \\
\hline \multicolumn{4}{|l|}{ Mortality } \\
\hline & OR & $\begin{array}{l}\text { Confidence } \\
\text { interval 95\% }\end{array}$ & $p$ \\
\hline Sex female & 1.34 & 1.08 to 1.65 & 0.006 \\
\hline History of prematurity & 1.24 & 0.84 to 1.82 & 0.409 \\
\hline Bronchopulmonary dysplasia & 1.69 & 1.07 to 2.67 & $<0.001$ \\
\hline Congenital heart disease & 3.40 & 2.65 to 4.37 & $<0.001$ \\
\hline In-hospital complications & 7.87 & 5.75 to 10.78 & $<0.001$ \\
\hline Invasive medical procedures & 11.17 & 8.14 to 15.33 & $<0.001$ \\
\hline Diagnosis at pneumonia & 4.25 & 3.30 to 5.47 & $<0.001$ \\
\hline
\end{tabular}


thus, patients with a history of prematurity are susceptible to airway infections, particularly of viral etiology [19]. Furthermore, patents with a history of prematurity have acquired dysfunction of the autonomic nervous system that might result from an inflammatory cascade induced by a virus, which can cause apnea, increasing the risk of death $[13,20]$. Additionally, patients with a history of premature birth present structural changes in the lung, including increased bronchial muscle, collagen, and elastin. Moreover, premature exposure to high oxygen tension and growth restriction as well as other aspects of the extrauterine environment worsen these effects $[21,22]$. These conditions have shown, as in the results of our study, that patients with a history of prematurity have greater comorbidities in addition to a VRI greater severity and, therefore, a longer hospital stay [23].

The presence of some invasive medical procedure as a risk factor for poor prognosis can serve as an indirect indicator of the severity of the case. The most frequent procedures were bronchoscopy and the placement of a central venous catheter because these patients will require long-term administration of medications.

RSV is the main respiratory pathogen in children under 2 years of age, and reinfection is common. Recent studies have been shown that hospitalizations of patients for respiratory infections in children under 4 years of age were predominantly for disease of viral etiology; of these, only $10 \%$ were due to rhinovirus, and the remaining $90 \%$ were due to RSV or in combination with rhinovirus and bocavirus [24]. Current guidelines recommend the prevention of RSV diseases with emphasis on hygienic measures and immunoprophylaxis as crucial aspects for reducing the transmission of this pathogen, especially in children with comorbidities $[25,26]$. It is worth mentioning that none of the patients included in this study received immunoprophylaxis for RSV, as it is not a drug available for patients attending the IMSS. Overall, compared with other publications [12], this study identifies a longer hospital stay, in-hospital complications and mortality in the group of patients with a history of prematurity, BPD and CHD.

It is important to mention that the sources of data collection include the population that attends the 3 levels of medical care, offering a broad perspective of disease behavior in Mexico.

Our study has limitations. First, patients with CHD and BPD were not classified according to the severity of these diseases, as patients with complex heart disease and severe BPD have a higher risk of complications compared to patients with CHD with low hemodynamic impact or mild BPD. Second, this study was performed with a secondary analysis of a database, whereby the diagnosis of VRI was considered through the codes registered in this database; in Mexico, a diagnosis is usually made based on clinical data and considering that $90 \%$ of respiratory airway infections in patients under 2 years of age have a viral etiology. Third, socioeconomic levels were not included in the analysis, though this factor has been shown to impact complications in these patients [27].

Mexico does not have established guidelines for the prevention and etiological diagnosis of lower respiratory infections, which generates a significant delay and an increase in the costs of care for these patients. Therefore, based on this study's results, we recommend making clinical guidelines identifying the patients with greater complication risks.

\section{Conclusions}

Patients between 1 and 24 months of age hospitalized for VRI with some existing pathology, such as prematurity, BPD and CHD, invasive medical procedures and diagnosis of pneumonia, are most affected by in-hospital complications. Factors associated with the mortality of patients between 1 and 24 months of age hospitalized for VRI were $\mathrm{BDP}, \mathrm{CHD}$, invasive medical procedures, inhospital complications and diagnosis of pneumonia.

Finally, a strategy that should be implemented is the use of inmunoprophylaxis for RSV in patients with prematurity, BPD, and/or CHD to prevent complications in this risk population.

\section{Abbreviations \\ VRI: Viral respiratory infections; RSV: Respiratory syncytial virus; PICU: Pediatric intensive care unit; BPD: Bronchopulmonary dysplasia; CHD: Congenital heart disease; IMSS: Mexican Social Security Institute; ICD 10: International Classification of Diseases; wGA: weeks of gestational age; C195\%: Confidence interval 95\%}

\section{Acknowledgements}

Not applicable.

\section{Informed consent}

According to the Helsinki Declaration, the protocol was approved by the National Research Ethics Committee, which belongs to the Mexican Institute of Social Security. This committee is the body in charge of evaluating research projects at the national level. The registry number R-2014-785-024. For this study, it was not necessary to request informed consent because it is a secondary analysis of a database obtained to record data from the hospitals affiliated with the IMSS.

\section{Authors' contributions}

JZC analyzed, interpreted the data and wrote the article. AGG, JEFG \& RACG analyzed and interpreted the data. LMA, MLAF, RSA \& GVR provided the critical review for important intellectual content, wrote the discussion and approved the final version of the article. NCS designed the study design and acquired information. All authors have read and approved the manuscript.

\section{Funding}

The research had no funding support.

\section{Availability of data and materials}

The datasets generated and/or analysed during the current study are not publicly available due, because it is a secondary analysis of a database obtained to record data from the hospitals affiliated with the IMSS and belongs to the IMSS, but are available from the corresponding author on reasonable request. 


\section{Ethics approval and consent to participate}

According to the Helsinki Declaration, the protocol was approved by the National Research Ethics Committee, which belongs to the Mexican Institute of Social Security. This committee is the body in charge of evaluating research projects at the national level. The registry number R-2014-785-024.

\section{Consent for publication}

Not applicable.

\section{Competing interests}

The authors declare that they have no competing interests.

\section{Author details}

${ }^{1}$ School of Medicine, Universidad Nacional Autónoma de Mexico, Mexico City, Mexico. ${ }^{2}$ Hospital Infantil de Mexico Federico Gómez, Mexico City, Mexico. ${ }^{3}$ Unit of Research in Medical Nutrition, Pediatric Hospital "Centro Médico Nacional Siglo XXI", Instituto Mexicano del Seguro Social (IMSS), Mexico City, Mexico. ${ }^{4}$ Computer Research Center of Instituto Politecnico Nacional, Mexico City, Mexico. ${ }^{5}$ Endocrine Research Unit, Centro Médico Nacional, Instituto Mexicano del Seguro Social (IMSS), Mexico City, Mexico. ${ }^{6}$ Epidemiological Surveillance Coordination, Instituto Mexicano del Seguro Social (IMSS), Mexico City, Mexico. ${ }^{7}$ Health Research Coordination, Instituto Mexicano del Seguro Social (IMSS), Mexico City, Mexico. ${ }^{8}$ Infectology Department, Pediatric Hospital "Centro Médico Nacional Siglo XXI", Instituto Mexicano del Seguro Social (IMSS), Mexico City, Mexico.

Received: 17 September 2019 Accepted: 1 June 2020

Published online: 09 June 2020

\section{References}

1. Friedman JN, Rieder MJ, Walton JM, Canadian Paediatric Society, Acute Care Committee DT and HSC. Bronchiolitis: recommendations for diagnosis, monitoring and management of children one to 24 months of age. Paediatr Child Heal. 2014;19(9):485-98

2. Hall CB, Weinberg GA, Iwane MK, et al. The burden of respiratory syncytial virus infection in young children. N Engl J Med. 2009;360(6):588-98.

3. Pierangeli A, Scagnolari CAG. Respiratory syncytial virus. Minerva Pediatr. 2018;70(6):553-65

4. Mauskopf J, Margulis AV, Samuel MLK. Respiratory syncytial virus hospitalizations in healthy preterm infants: systematic review. Pediatr Infect Dis J. 2016;35(7):e229-38.

5. Bohmwald K, Espinoza JA, Rey-Jurado E, Gómez RS, González PA, Bueno SM Riedel CAKA. Human respiratory syncytial virus: infection and pathology. Semin Respir Crit Care Med. 2016;37(4):522-37.

6. Zanone SM, Krause LK, Madhi SA, Bassat Q, Jha P, Simões EA, Wairagkar NPFR. And CMWG. Challenges in estimating RSV-associated mortality rates. Lancet Respir Med. 2016:4(5):345-7.

7. Tracy MKBS. Bronchopulmonary dysplasia and pulmonary outcomes of prematurity. Pediatr Ann. 2019;48(4):e148-53.

8. Cheong JLYDL. An update on pulmonary and neurodevelopmental outcomes of bronchopulmonary dysplasia. Semin Perinatol. 2018;42(7):478-84.

9. Day CLRR. Bronchopulmonary dysplasia: new becomes old again! Pediatr Res. 2017:81(1-2):210-3.

10. Voynow JA. "New" bronchopulmonary dysplasia and chronic lung disease. Paediatr Respir Rev. 2017;24:17-8

11. Tulloh RMR, Medrano-Lopez C, Checchia PA, Stapper C, Sumitomo N, Gorenflo M, Jung Bae E, Juanico A, Gil-Jaurena JM, Wu MH, Farha T, Dodge-Khatami A Tsang R, Notario GWC. CHD and respiratory syncytial virus: global expert exchange recommendations. Cardiol Young. 2017;27(8):1504-21.

12. Friedman D, Fryzek J, Jiang X, Bloomfield A, Ambrose CSWP. Respiratory syncytial virus hospitalization risk in the second year of life by specific congenital heart disease diagnoses. PLoS One. 2017;12(3):e0172512.

13. Ricart S, Rovira N, Garcia-Garcia JJ, Pumarola T, Pons M, Muñoz-Almagro CMM. Frequency of apnea and respiratory viruses in infants with bronchiolitis. Pediatr Infect Dis J. 2014;33(9):988-90

14. Kanakoudi-Tsakalidou F, Debonera F, Drossou-Agakidou V, Sarafidis K, Tzimouli V, Taparkou AKG. Flow cytometric measurement of HLA-DR expression on circulating monocytes in healthy and sick neonates using monocyte negative selection. Clin Exp Immunol. 2001;123(3):402-7.
15. Lee JH, Noh OKCYKNN. Neonatal outcomes of very low birth weight infants in Korean neonatal network from 2013 to 2016. J Korean Med Sci. 2019; 34(5):e40

16. Samuel N, Hershkovitz T, Brik R, Lorber ASI. Diagnosing heart failure in children with congenital heart disease and respiratory syncytial virus bronchiolitis. Am J Emerg Med. 2014;32(12):1510-2..

17. Kristensen K, Hjuler T, Ravn H, Simões EASL. Chronic diseases, chromosomal abnormalities, and congenital malformations as risk factors for respiratory syncytial virus hospitalization: a population-based cohort study. Clin Infect Dis. 2012;54(6):810-7.

18. Tibbles CD, Bouton M, Lucas JM, Harper M, Horwitz CFJ. Emergency department management of pediatric patients with cyanotic heart disease and fever. J Emerg Med. 2013:44(3):599-604.

19. Heinonen S, Rodriguez-Fernandez R, Diaz A, Oliva Rodriguez-Pastor S, Ramilo OMA. Infant immune response to respiratory viral infections. Immunol Allergy Clin N Am. 2019;39(3):361-76

20. Rehder KJ, Wilson EA, Zimmerman KO, Cunningham CKTD. Detection of multiple respiratory viruses associated with mortality and severity of illness in children. Pediatr Crit Care Med. 2015;16(7):e201-6.

21. Prince LR, Maxwell NC, Gill SK, Dockrell DH, Sabroe I, McGreal EP, Kotecha SWM. Macrophage phenotype is associated with disease severity in preterm infants with chronic lung disease. PLoS One. 2014;9(8):e103059.

22. Drysdale SB, Alcazar-Paris M, Wilson T, Smith M, Zuckerman M, Broughton S, Rafferty GF, Peacock JL, Johnston SLGA. Rhinovirus infection and healthcare utilisation in prematurely born infants. Eur Respir J. 2013;42(4):1029-36.

23. Gunville CF, Sontag MK, Stratton KA, Ranade DJ, Abman SHMP. Scope and impact of early and late preterm infants admitted to the PICU with respiratory illness. J Pediatr. 2010;157(2):209-214.e1.

24. Cebey-López M, Herberg J, Pardo-Seco J, Gómez-Carballa A, Martinón-Torres N, Salas A, Martinón-Sánchez JM, Justicia A, Rivero-Calle I, Sumner E, Fink C M-TFG network. Does Viral Co-Infection Influence the Severity of Acute Respiratory Infection in Children? PLoS One. 2016;11(4):e0152481.

25. American Academy of Pediatrics Committee on Infectious Diseases; American Academy of Pediatrics Bronchiolitis Guidelines Committee. Updated guidance for palivizumab prophylaxis among infants and young children at increased risk of hospitalization for respiratory syncytial virus infection. Pediatrics. 2014:134(2):415-20.

26. Ralston SL, Lieberthal AS, Meissner HC, Alverson BK, Baley JE, Gadomski AM, Johnson DW, Light MJ, Maraqa NF, Mendonca EA, Phelan KJ, Zorc JJ, Stanko-Lopp D, Brown MA, Nathanson I, Rosenblum E, Sayles S 3rd. H-CSAA of $P$. clinical practice guideline: the diagnosis, management, and prevention of bronchiolitis. Pediatrics. 2014:134(5):e1474-502.

27. Karppinen S, Toivonen L, Schuez-Havupalo L, Waris MPV. Interference between respiratory syncytial virus and rhinovirus in respiratory tract infections in children. Clin Microbiol Infect. 2016;22(2):208.e1-6.

\section{Publisher's Note}

Springer Nature remains neutral with regard to jurisdictional claims in published maps and institutional affiliations.

Ready to submit your research? Choose BMC and benefit from:

- fast, convenient online submission

- thorough peer review by experienced researchers in your field

- rapid publication on acceptance

- support for research data, including large and complex data types

- gold Open Access which fosters wider collaboration and increased citations

- maximum visibility for your research: over $100 \mathrm{M}$ website views per year

At BMC, research is always in progress.

Learn more biomedcentral.com/submissions 